\title{
Evaluation of Simulated Clear-Sky Longwave Radiation Using Ground-Based Observations
}

\author{
RichARD P. ALLAN* \\ Department of Meteorology, University of Reading, Reading, Berkshire, United Kingdom
}

(Manuscript received 5 January 1999, in final form 3 June 1999)

\begin{abstract}
Surface observations from a tropical ocean and a subarctic land-based site are employed to evaluate the clearsky surface downwelling longwave irradiance (SDL) simulated using the European Centre for Medium-Range Weather Forecasts reanalysis (ERA). Comparison of simulated clear-sky and observed all-sky SDL highlights coincident periods of irradiance variability on various timescales in both datasets. Measurements during cloudy conditions are subsequently removed using a combination of the measured shortwave and longwave surface irradiances and recorded rainfall. The most reasonable filtering specifications are determined experimentally; clear-sky filtered observations of SDL are compared with corresponding simulated values. The root-mean-square differences between simulated and observed clear-sky SDL are within the observational uncertainty of $\pm 10 \mathrm{~W}$ $\mathrm{m}^{-2}$. Simulated clear-sky SDL is about $8 \mathrm{~W} \mathrm{~m}^{-2}$ more than the measured tropical values. In the subarctic, the simulated clear-sky SDL is less than observed values in the winter and greater than observed values in the summer. The clear-sky SDL differences are explained partially by the differences in ERA moisture profiles and near-surface temperature in comparison with radiosonde ascents. A primary limitation of the radiometric measurements is the lack of information regarding cloud amount; if model-simulated clear-sky fluxes and cloud radiative forcing are to be fully evaluated, it is highly desirable that such information should accompany surfacebased radiation data.
\end{abstract}

\section{Introduction}

The atmospheric emission of longwave radiation to the surface constitutes a significant component of the surface energy balance. It is also an important parameter with regard to the water vapor feedback to changing surface temperature: increases in water vapor amount in the troposphere, a likely response to surface warming (IPCC 1996), will lead to increased emission of longwave radiation from the atmosphere to the surface. Modeling studies indeed show the clear-sky surface downwelling longwave irradiance $\left(\mathrm{SDL}_{\mathrm{c}}\right)$ to be an important amplifier of greenhouse gas-forced surface warming by way of a strong water vapor feedback (e.g., Ramanathan 1981). It is therefore important that $\mathrm{SDL}_{c}$ is simulated adequately by climate models, particularly where the surface irradiance is included as part of a flux into fully dynamic oceans (e.g., Johns et al. 1997).

\footnotetext{
*Current affiliation: Hadley Centre for Climate Prediction and Research, Meteorological Office, Bracknell, Berkshire, United Kingdom.

Corresponding author address: Dr. R. P. Allan, Hadley Centre, The Met. Office, London Road, Bracknell, Berkshire RG12 2SY, United Kingdom.

E-mail: rpallan@meto.gov.uk
}

In evaluating simulated surface irradiances, it is necessary to highlight uncertainties within the radiation scheme used in the model, the input data to the radiation scheme, and the observations with which models are compared. Dutton (1993) compared observed SDL, filtered to remove cloudy observations, with values calculated by applying a radiative transfer scheme to radiosonde profiles. The model-observation difference was found to fall within the, albeit large, experimental error. Wild et al. (1995) compared surface irradiance simulated by a climate model with both surface observations and also radiative transfer calculations using radiosonde profiles as input data. Model $\mathrm{SDL}_{\mathrm{c}}$ tended to be underestimated by about $5 \mathrm{~W} \mathrm{~m}^{-2}$ in comparison with radiative transfer scheme calculations and $10 \mathrm{~W}$ $\mathrm{m}^{-2}$ when compared with surface irradiance observations. A similar result was found by Garratt and Prata (1996), who compared all-sky SDL simulated by four climate models with observations over continental surfaces. They argued that the model underestimate in SDL was caused by underestimates in near-surface temperature. The bias was less apparent in a subsequent study (Garratt et al. 1998), and satellite-derived SDL was greater than observed global mean land values. More recently, Wild et al. (1998) argued that climate models generally underestimate $\mathrm{SDL}_{\mathrm{c}}$ and that realistic hydrological cycles resulted only because the same models overestimated the surface absorbed solar radiation. 
Validation of model-simulated surface irradiance is limited by the observational network. The accuracy of ground-based radiometers is about $\pm 10 \mathrm{~W} \mathrm{~m}^{-2}$ (e.g., Weller and Anderson 1996). Also, the surface network of radiometers is spatially limited and confined almost exclusively to land-based regions (e.g., Garratt and Prata 1996). The need to derive clear-sky observations, in order to compare with model clear-sky irradiance, reduces the spatial and temporal coverage still further. One possible solution to this problem is to infer radiative fluxes at the surface by using satellite radiances at the top of the atmosphere (e.g., Gupta 1989). Using this method, Rossow and Zhang (1995) found model-observation all-sky SDL differences to be large; this is unsurprising considering that the SDL is dependent mainly on near-surface conditions, which are the most difficult variables to derive remotely from satellite. Indeed, temperature and humidity fields near to the surface are highly important in determining clear-sky SDL (e.g., Zhao et al. 1994).

An alternative method of estimating the $\mathrm{SDL}_{\mathrm{c}}$ is used in the present study. A simulation of the earth's clearsky longwave radiation budget is employed (Slingo et al. 1998) that exploits the European Centre for MediumRange Weather Forecasts (ECMWF) reanalysis (ERA). The objective of the present study is twofold. First, the ability of the simulation to reproduce the observed SDL and its variability is evaluated. Second, the potential usefulness of surface radiometric measurements in validating climate model surface fluxes is assessed. Observational data from the tropical central Pacific and a land-based subarctic site are utilized, thereby sampling contrasting climatic regimes. The datasets are described in section 2 along with a preliminary comparison with the simulation. Section 3 outlines the method used to sample clear-sky measurements of SDL. A detailed evaluation of simulated $\mathrm{SDL}_{\mathrm{c}}$, using the filtered clear-sky measurements and additional observed atmospheric profiles, is subsequently undertaken in section 4 . Causes and implications of differences between the observed and simulated $\mathrm{SDL}_{\mathrm{c}}$ are discussed in the final section.

\section{Datasets and initial comparisons}

\section{a. Simulated clear-sky longwave irradiance}

Simulations of clear-sky longwave radiative fluxes and heating rates were performed using a comprehensive reanalysis of atmospheric variables for a $15-\mathrm{yr}$ period (ERA; Gibson et al. 1997) as input for the Edwards and Slingo (1996) radiation code. The simulation, clearsky longwave radiation from ERA (CLERA) was described in detail by Slingo et al. (1998). Errors inherent in ERA (e.g., Kållberg 1998) are likely to affect CLERA. Column water vapor and near-surface temperatures are likely to constitute the largest uncertainties with regard to the simulated $\mathrm{SDL}_{\mathrm{c}}$ (e.g., Zhao et al. 1994). The present study uses the $2.5^{\circ}$ lat $\times 2.5^{\circ}$ long gridpoint 6-h simulated $\mathrm{SDL}_{\mathrm{c}}$ in conjunction with the ERA data.

\section{b. Observations in the tropical Pacific}

Observations from the Woods Hole Oceanographic Institution (WHOI) floating buoy were presented by Weller and Anderson (1996) and formed part of the Tropical Ocean Global Atmosphere Coupled OceanAtmosphere Response Experiment [TOGA COARE; described in Webster and Lukas (1992)]. The mooring was positioned at $1.75^{\circ} \mathrm{S}, 156^{\circ} \mathrm{E}$, situated in the tropical warm pool region. All-sky longwave irradiance was measured using a precision infrared radiometer (PIR), which is sensitive to radiation mainly between 4 and $50 \mu \mathrm{m}$ (about $200-2500 \mathrm{~cm}^{-1}$ ). In situ cloud observations could not be recorded due to the automatic nature of the station. Hourly averaged irradiance observations were utilized from 21 October 1992 to 4 March 1993 with additional radiosonde retrievals of atmospheric temperature and moisture from the adjacent Kavieng, Papua New Guinea, site at $2.6^{\circ} \mathrm{S}$, $150.8^{\circ} \mathrm{E}$ as part of the Atmospheric Radiation Measurement (ARM) Program (e.g., Long 1996). All data were acquired from the TOGA COARE data information system (http://wwwarc.essc.psu.edu/data/ togacoare/TOGACOAREdataindex.html). Comparison with the nearest ERA gridpoint values was undertaken.

\section{c. Subarctic observations}

Measurements of all-sky surface irradiance at Barrow, Alaska $\left(71.3^{\circ} \mathrm{N}, 156.6^{\circ} \mathrm{W}\right)$, throughout 1992 were obtained from the Solar and Thermal Atmospheric Radiation (STAR) group at http://www.cmdl.noaa.gov/star/. Radiosonde profiles and additional surface observations from the Barrow site were also utilized, although no information on cloud amount was available. Hourly averaged measurements of SDL by Eppley Precision Infrared Radiometers (PIR) from 3 January to 28 December 1992 were compared with the average of the 6-h simulated $\mathrm{SDL}_{\mathrm{c}}$ from the four surrounding grid points bounded by $70^{\circ}-72.5^{\circ} \mathrm{N}$ and $155^{\circ}-157.5^{\circ} \mathrm{W}$.

\section{d. Preliminary comparison}

A direct comparison between simulated and observed variables is now briefly considered to illustrate the respective climatic regimes of each site. This ensures that variability on a range of timescales, which may be obscured in the clear-sky comparisons, is adequately represented. At the tropical site the high atmospheric temperature and moisture dictate that the observed all-sky and simulated clear-sky SDL are generally greater than $400 \mathrm{~W} \mathrm{~m}^{-2}$ (Fig. 1a). The similar magnitude of the observed and CLERA irradiances suggests that the effect of clouds on the SDL is small. Irradiance fluctuations are coincident in both time series (Fig. 1a), the 
(a) CLERA 6-hourly SDLC and WHOI 6-hourly averaged SDL
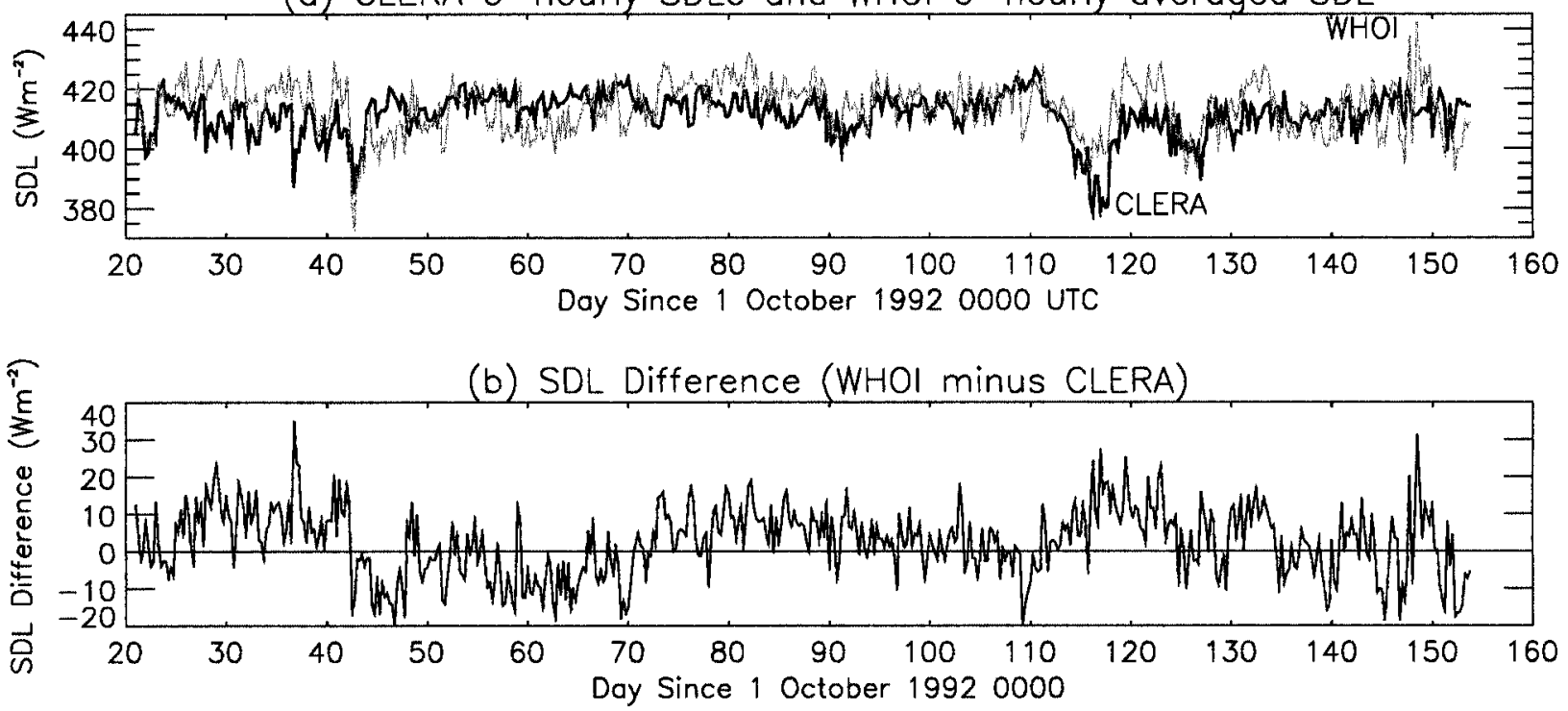

(c) ERA sea surface temperature and WHOI ocean skin temperature

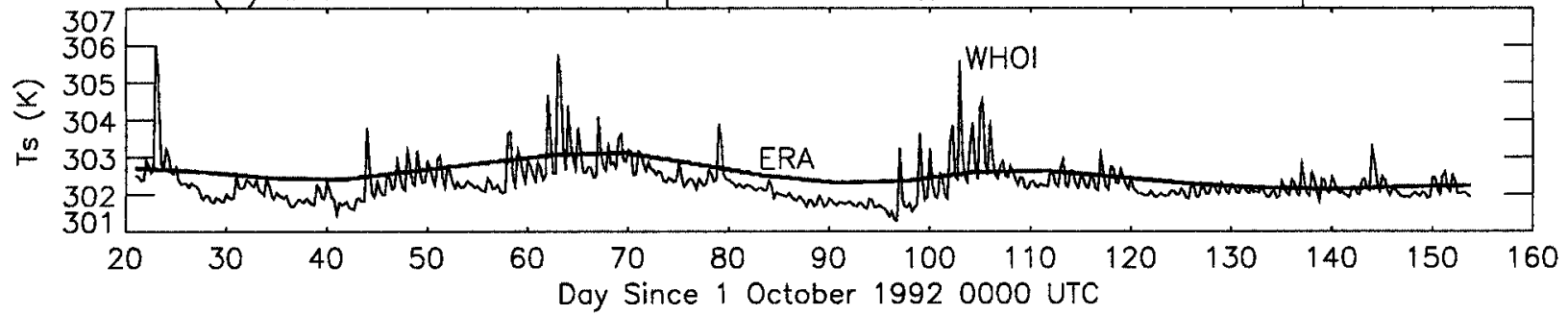

FIG. 1. Time series of hourly averaged observations from the WHOI floating buoy and 6-h ERA and CLERA data at $1.75^{\circ} \mathrm{N}, 156^{\circ} \mathrm{E}$ for the the period 21 Oct 1992-4 Mar 1993. (a) WHOI and CLERA SDL (W m $\left.{ }^{-2}\right)$; (b) WHOI - CLERA SDL difference (W m $\left.{ }^{-2}\right)$; and (c) WHOI and ERA surface skin temperature $T_{s}(\mathrm{~K})$.

most notable being late January (days 110 to 120) and mid-November (days 40-45). Periods of active and suppressed convective phases of the intraseasonal oscillation (ISO; e.g., Gutzler et al. 1994) provide one mechanism for irradiance variability on various timescales (e.g., Weller and Anderson 1996). It is evident from Fig. $1 \mathrm{~b}$ that there are periods when observed all-sky minus simulated clear-sky SDL is negative. The additional longwave emission from clouds should ensure that the observed SDL remains greater than the CLERA values, thus indicating errors in the simulation and/or the observations. This point will be revisited in section 4 . Observed sea surface temperature is observed to vary markedly over the diurnal cycle (Fig. 1c), although this is not captured by ERA, which uses the Reynolds and Smith (1994) sea surface temperature dataset.

The subarctic site contrasts greatly with the warm, moist tropical warm pool, with cold, mainly overcast conditions prevailing (e.g., Stone 1997). Unlike the tropical warm pool, there exists a strong seasonal cycle due to the large variability in incident solar radiation. This results in a large observed annual surface temperature cycle, which is reproduced by the ERA data (Fig. 2a). Notably, an overestimation of surface temperature by ERA, compared to observed values, occurred during late April. Total column water vapor $(u)$ also varies markedly, ranging from about $1 \mathrm{~kg} \mathrm{~m}^{-2}$ during late January up to $30 \mathrm{~kg} \mathrm{~m}^{-2}$ at the end of June (Fig. 2b). The simulated $\mathrm{SDL}_{\mathrm{c}}$ shows a strong correlation with temperature and moisture fluctuations and thus also displays a large annual cycle (Fig. 2c). A similar amplitude in the all-sky SDL observations highlights the importance of the clear-sky atmosphere on the irradiance variability. However, large differences of up to $100 \mathrm{~W} \mathrm{~m}^{-2}$ for observed SDL minus simulated $\mathrm{SDL}_{\mathrm{c}}$ are present indicating a significant influence of clouds on the surface longwave radiative fluxes.

\section{Clear-sky detection}

Evaluation of simulated $\mathrm{SDL}_{\mathrm{c}}$ necessitates the extraction of cloud-free periods in the all-sky datasets. However, removing measurements from the time series that are deemed to be taken during cloudy conditions is problematic due to the lack of in situ observations of 

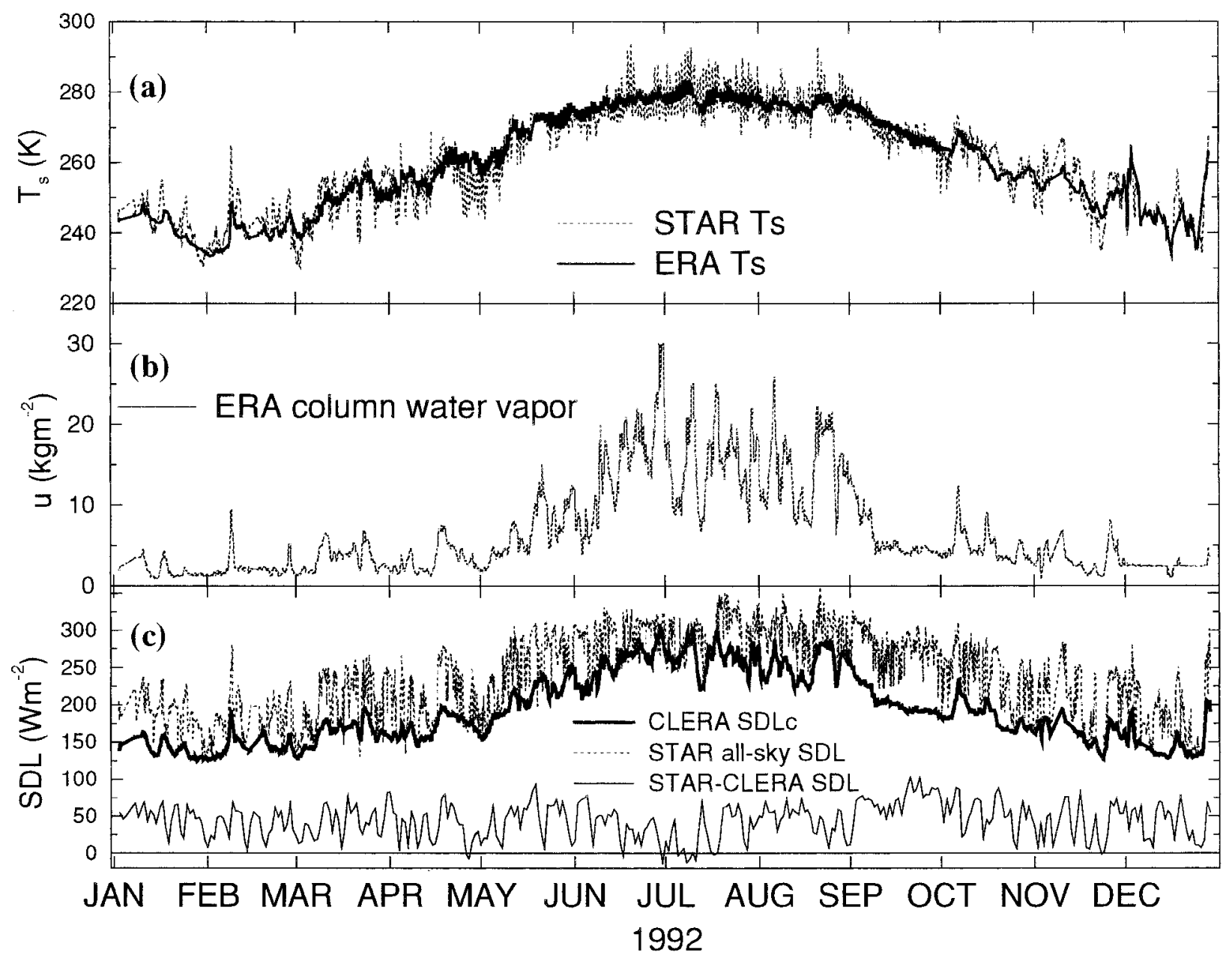

FIG. 2. Time series of hourly averaged STAR observations and 6-h ERA and CLERA data for Barrow $\left(72.3^{\circ} \mathrm{N}, 156.6^{\circ} \mathrm{W}\right), 1992$. (a) Surface temperature $T_{s}(\mathrm{~K})$ for STAR and ERA; (b) ERA column mean water vapor $u\left(\mathrm{~kg} \mathrm{~m}^{-2}\right)$; and (c) STAR and CLERA SDL (W m $\left.{ }^{-2}\right)$, and the STAR - CLERA SDL difference.

cloud amount at either site. Two alternative methods were used to identify clear-sky periods.

\section{a. Solar method}

The so-called CET method of Waliser et al. (1996) was adapted for the two locations to estimate the clearsky surface downwelling shortwave irradiance $\left(\mathrm{SW}_{\mathrm{clr}}\right)$. Skies were assumed to be clear when the observed downwelling shortwave irradiance at the surface $\left(\mathrm{SW}_{\text {sfc }}\right)$ was greater than a fraction $k_{\mathrm{sw}}$ of $\mathrm{SW}_{\mathrm{clr}}$ given by

$$
\mathrm{SW}_{\text {clr }}=S_{0} \epsilon \mu \tau \text {, }
$$

where $S_{0}$ is the solar constant $\left(1368 \mathrm{~W} \mathrm{~m}^{-2}\right), \epsilon$ is the square of the instantaneous Earth-Sun distance normalized by the mean distance, and $\mu$ is the cosine of the solar zenith angle. The atmospheric transmission $\tau$ was calculated using a narrowband radiative transfer scheme (Forster and Shine 1997) applied to tropical and subarctic summer standard atmospheres (McClatchey et al. 1972) for a range of values of $\mu$ and $u$. Absorption by carbon dioxide, water vapor, and ozone were included in the narrowband computations. The effects of aerosols were not considered because of the lack of relevent information at the observing sites. The form of $\tau$ is similar to the algorithm of Waliser et al. (1996), being a fifth-order polynomial with the addition of a weak dependence on $u$;

$$
\begin{aligned}
\tau(\mu, u)= & \left(a_{0}+a_{1} \mu+a_{2} \mu^{2}+a_{3} \mu^{3}+a_{4} \mu^{4}+a_{5} \mu^{5}\right) \\
& +\left(b_{0}+b_{1} \mu\right)\left(u^{0.5}-b_{2}\right) .
\end{aligned}
$$

The constants in (2) are displayed for the tropical and subarctic sites in Table 1. Values of $u\left(\mathrm{~kg} \mathrm{~m}^{-2}\right)$ are prescribed by ERA 6-h values. This formula approximates $\mathrm{SW}_{\mathrm{clr}}$ to within $\pm 2.5 \mathrm{~W} \mathrm{~m}^{-2}$ of the narrowband calculated values.

Figure 3 shows the calculated $\mathrm{SW}_{\text {clr }}$ plotted with allsky observed $\mathrm{SW}_{\text {sfc }}$ from the tropical and the subarctic sites. The banded structure in Fig. $3 \mathrm{a}$ is a result of the 
TABLE 1. Regression coefficients for the tropical and subarctic $\mathrm{SW}_{\mathrm{clr}}$ models.

\begin{tabular}{cccccccccc}
\hline \hline Site & $a_{0}$ & $a_{1}$ & $a_{2}$ & $a_{3}$ & $a_{4}$ & $a_{5}$ & $b_{0}$ & $b_{1}$ & $b_{2}$ \\
\hline Tropical & 0.354 & 2.274 & -6.105 & 9.261 & -7.174 & 2.198 & -0.0152 & 0.00293 & 6.40 \\
Subarctic & 0.335 & 2.991 & -10.39 & 20.97 & -21.98 & 9.221 & -0.0209 & 0.00668 & 4.57 \\
\hline
\end{tabular}

small variability of solar insolation at the top of the atmosphere for a given hour of the day at the tropical site. This is not evident in Fig. 3 b because of the large subarctic annual solar cycle. Points to the right of the solid lines, $\mathrm{SW}_{\mathrm{sfc}}=k_{\mathrm{sw}} \mathrm{SW}_{\mathrm{clr}}$, are retained as clear-sky observations determined for the given values of $k_{\mathrm{sw}}$. By increasing $k_{\mathrm{sw}}$ the number of clear-sky observations is therefore reduced. Values were only considered for $\mu$ $>0.1$ and where no rainfall was recorded.

\section{b. Longwave method}

The solar method is problematic, particularly for the subarctic site, as only daylight hours could be exploited. Also, cloud information may only be inferred from the local solar azimuth-zenith angle (Dutton 1993). Thus for the subarctic site an additional clear-sky detection method was developed whereby the sky was assumed clear when SDL was below a specified fraction $k_{\mathrm{lw}}$ of the surface-emitted irradiance $E$. Dutton (1993) argued that the longwave method is not suitable for tropical environments because of low-level moisture obscuring the cloud signal in the net longwave irradiance.

The longwave method is illustrated in Fig. 4, which shows the observed surface-emitted longwave irradiance plotted against observed SDL. The lines corre- spond to $E=k_{\mathrm{lw}} \mathrm{SDL}$ for two different values of $k_{\mathrm{lw}}$; points above each line are defined as clear-sky measurements for the given $k_{\mathrm{lw}}$. Thus by decreasing $k_{\mathrm{lw}}$ the number of measurements deemed to be made under clear-sky conditions is reduced. Using the SDL to identify clear-sky conditions is undesirable because it is the parameter from which model-observation comparison is undertaken: the strong dependence of SDL on parameters other than cloud amount will potentially introduce systematic biases into the clear-sky filtered data. For example, the strong apparent positive dependence of $\mathrm{SDL}_{\mathrm{c}}$ on temperature and column water vapor highlighted in Fig. 2 is likely to result in an oversampling of cold, dry profiles using the longwave method. This method is utilized because of the shortcomings of the solar method and the strong influence of clouds on the surface net longwave irradiance for the relatively dry subarctic profiles. Clear-sky sampling was performed for a variety of $k_{\mathrm{lw}}$. Comparisons were subsequently undertaken between observed and simulated $\mathrm{SDL}_{\mathrm{c}}$ considering only the portions of the time series deemed to be free of cloud cover.

\section{Evaluation of simulated clear-sky SDL}

The purpose of this section is to evaluate the simulated $\mathrm{SDL}_{\mathrm{c}}$ using the ground-based observations. The (a) Tropical West Pacific

(b) Barrow, Alaska

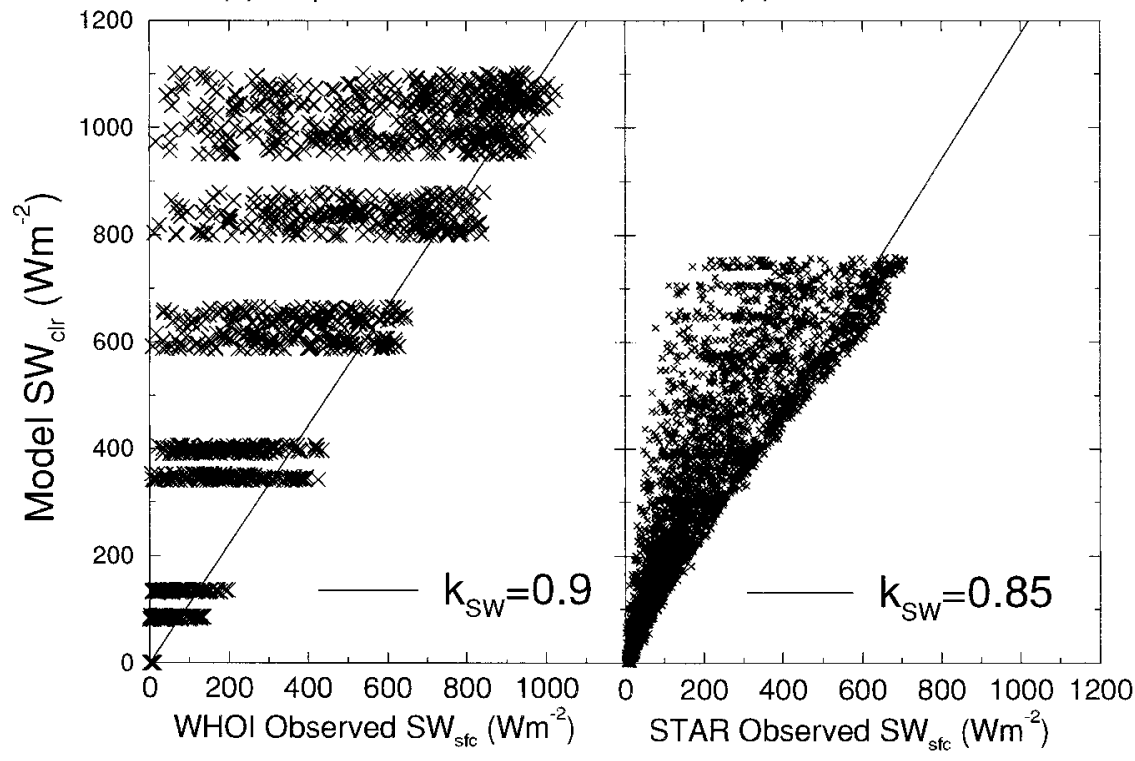

FIG. 3. Calculated $\mathrm{SW}_{\mathrm{ctc}}\left(\mathrm{W} \mathrm{m}^{-2}\right)$ plotted with observed $\mathrm{SW}_{\text {sfc }}\left(\mathrm{W} \mathrm{m}^{-2}\right)$ for (a) WHOI tropical Pacific hourly observations from Oct 1992 to Mar 1993 and (b) STAR hourly observations for 1992 at Barrow. The solid line denotes $\mathrm{SW}_{\mathrm{sfc}}=k_{\mathrm{sw}} \mathrm{SW}_{\mathrm{clr}}$ for (a) $k_{\mathrm{sw}}=0.9$ and (b) $k_{\mathrm{sw}}=0.85$. 


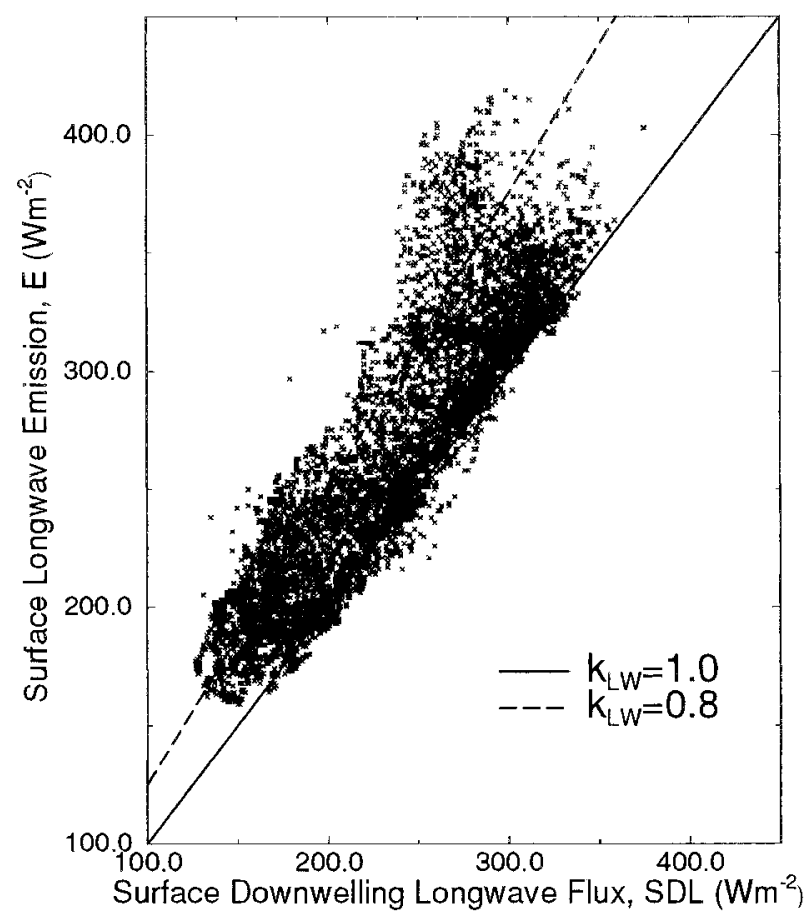

FIG. 4. STAR observations of hourly surface upwelling longwave irradiance plotted against observed SDL for 1992. Solid and dashed lines denote $E=k_{1 \mathrm{w}} \mathrm{SDL}$

all-sky measurements of SDL were filtered to extract clear-sky values using the method described in section 3. It is desirable to minimize cloud contamination in the clear-sky radiometric data while maximizing the number of suitable $\mathrm{SDL}_{\mathrm{c}}$ measurements. Decreasing $k_{\mathrm{lw}}$ and increasing $k_{\mathrm{sw}}$ is likely to reduce cloud contamination of the clear-sky measurements but also reduces the amount of clear-sky data. The optimum values of $k_{\mathrm{lw}}$ and $k_{\mathrm{sw}}$ were obtained by experiment.

\section{a. Tropical comparison}

The mean difference between observed minus simulated $\mathrm{SDL}_{\mathrm{c}}$ is plotted for a range of $k_{\mathrm{sw}}$ in Fig. 5a. The number of clear-sky observations are shown within the frame. The WHOI and CLERA means for all times are shown as filled symbols. The removal of values where rainfall was observed accounts for much of the difference between observed SDL at $k_{\mathrm{sw}}=0.0$ (open circles) and the mean of all observed values (filled circles) in Fig. 5b. This is because observations taken during rainfall will preferentially sample humid, overcast times of high longwave emission compared to other times. Simulated $\mathrm{SDL}_{\mathrm{c}}$ is also slightly higher when not filtered for observed rainfall; this is a likely occurrence of the higher column mean water vapor at times when rainfall was observed. The simulated $\mathrm{SDL}_{\mathrm{c}}$ changes only slightly with $k_{\mathrm{sw}}$ due to systematic changes in ERA temperature or moisture with observed cloud amount. For $k_{\mathrm{sw}}>1.0$,

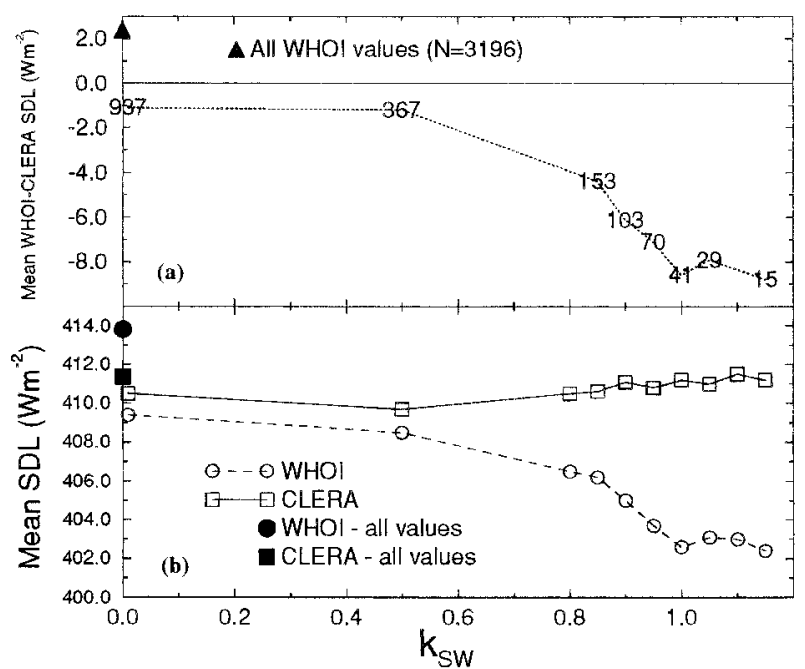

FIG. 5. Effect of varying $k_{\mathrm{sw}}$ on (a) the observed minus simulated clear-sky surface downwelling longwave irradiance difference and (b) the WHOI observed $\mathrm{SDL}_{\mathrm{c}}$ and interpolated CLERA simulated $\mathrm{SDL}_{\mathrm{c}}$ for times where no rainfall is recorded and $\mu>0.1$. Means of all values are also shown as a comparison (filled symbols). Numbers in (a) refer to the sample size of clear-sky observations.

further increases in $k_{\mathrm{sw}}$ yield marginally smaller decreases in mean observed $\mathrm{SDL}_{\mathrm{c}}$.

Setting $k_{\text {sw }}$ to 0.9 leaves 103 WHOI observations that are deemed cloud free, while 41 observations remain at $k_{\mathrm{sw}}=1.0$. A large number of these observations are during late November and early December indicating that this convectively suppressed ISO phase contains relatively more clear-sky periods than over the remaining TOGA COARE observation period. Observed $\mathrm{SDL}_{\mathrm{c}}$ is plotted against simulated $\mathrm{SDL}_{\mathrm{c}}$ for $k_{\mathrm{sw}}=0.9$ (crosses) and $k_{\mathrm{sw}}=1.0$ (squares) in Fig. 6. Values tend to be to the left of the 1:1 line showing lower observed $\mathrm{SDL}_{c}$ than simulated $\mathrm{SDL}_{\mathrm{c}}$. This finding is consistent with results from Dutton (1993), who found observed $\mathrm{SDL}_{\mathrm{c}}$ to be less than model-calculated values in the Tropics.

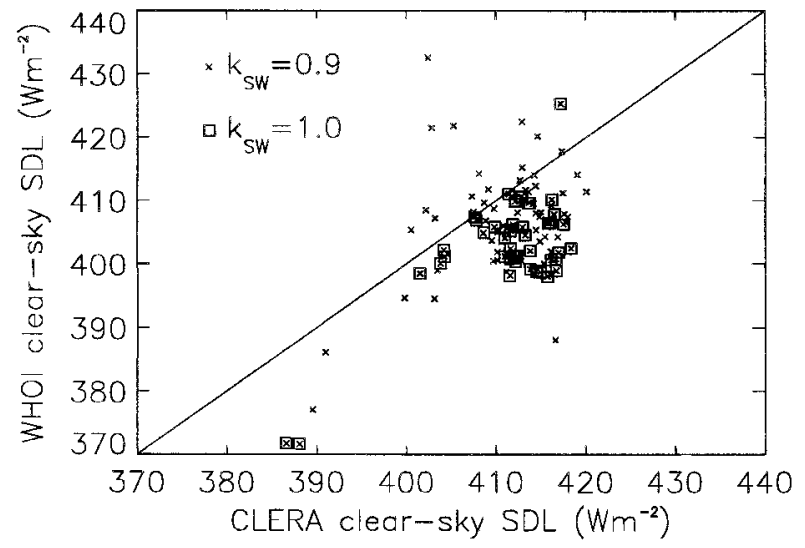

FIG. 6. (a) Clear-sky filtered WHOI SDL plotted against CLERA $\mathrm{SDL}_{\mathrm{c}}$ for $k_{\mathrm{sw}}=0.9$ (crosses) and $k_{\mathrm{sw}}=1.0$ (squares) over the TOGA COARE period. The solid line represents a 1:1 relationship. 


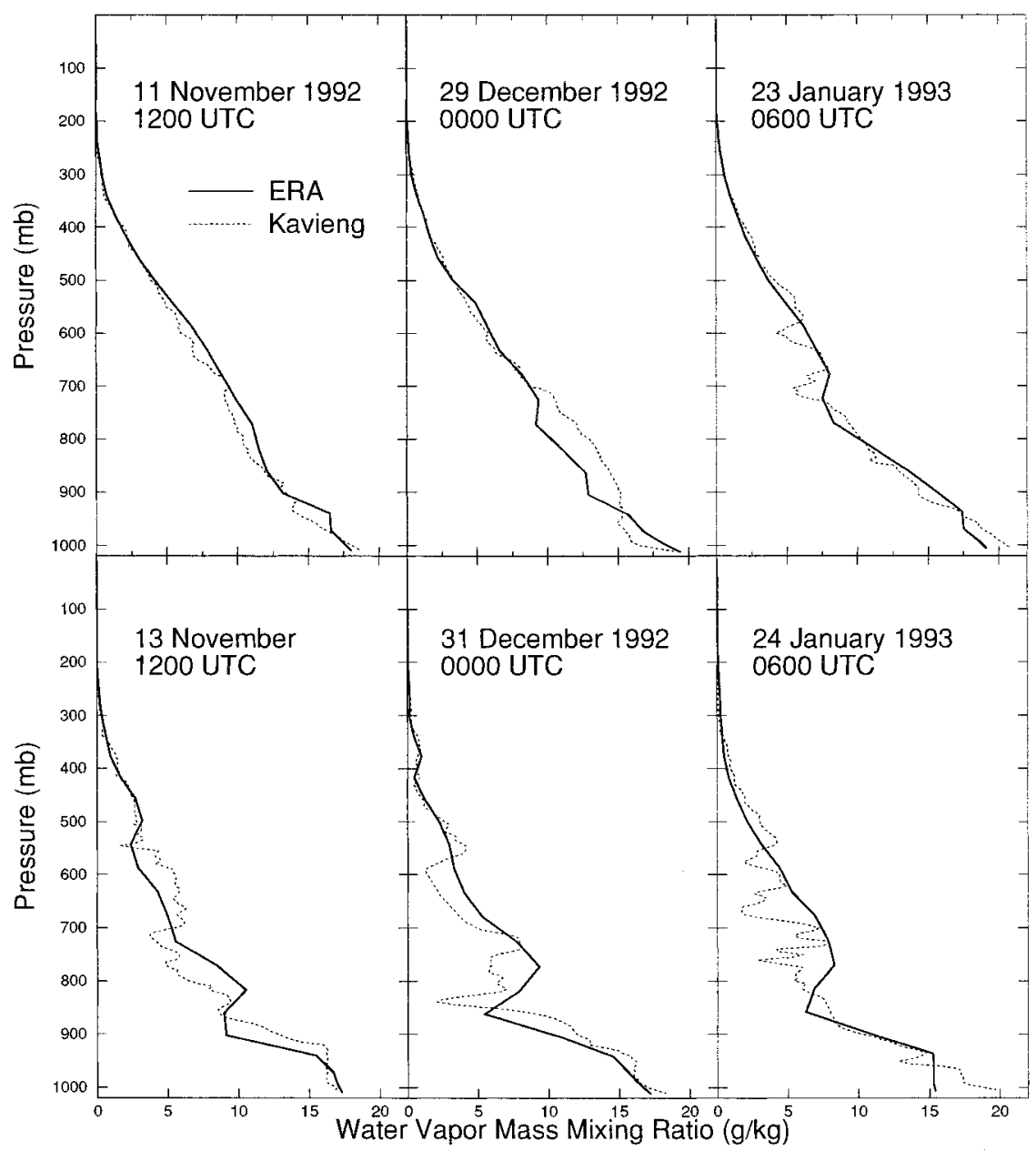

FIG. 7. ERA and Kavieng radiosonde profiles of water vapor mass mixing ratio. Location: $2.6^{\circ} \mathrm{S}, 150.8^{\circ} \mathrm{E}$.

The mean $\mathrm{SDL}_{\mathrm{c}}$ difference for $k_{\mathrm{sw}}=0.95$ is $7.1 \mathrm{~W} \mathrm{~m}^{-2}$ and may be explained either by a systematic error in the observations or by errors in the simulation. The rootmean-square difference between observed and simulated $\mathrm{SDL}_{\mathrm{c}}$ for $k_{\mathrm{sw}}=0.95$ is $8.4 \mathrm{~W} \mathrm{~m}^{-2}$, although when the systematic bias is removed this falls to $4.7 \mathrm{~W} \mathrm{~m}^{-2}$. Both values are within the observational uncertainty.

Radiosonde ascents over the ocean region sampled by the WHOI buoy are required to directly attribute errors in ERA temperature and moisture profiles to differences in $\mathrm{SDL}_{\mathrm{c}}$. However, the lack of available data necessitate the comparison of the ARM radiosonde ascents in conjunction with corresponding ERA profiles at the nearest grid point. These data sample the Kavieng island region on an adjacent grid point to the tropical comparison grid point; thus differences between ERA and radiosonde profiles may not represent the conditions relevant to the irradiance comparison, but they do illustrate potential causes of the $\mathrm{SDL}_{\mathrm{c}}$ differences. This is applicable primarily to near-surface temperatures, which are strongly modulated by the surface tempera- ture over land regions such as the Kavieng radiosonde launch site.

Figure 7 shows ERA and radiosonde water vapor mass mixing ratio profiles to be in good agreement. This suggests that differences between observed and simulated $\mathrm{SDL}_{\mathrm{c}}$ are unlikely to be caused primarily by errors in ERA humidity. Near-surface temperature for ERA profiles and ARM radiosonde profiles are shown in Fig. 8. Differences between surface temperatures by as much as $3 \mathrm{~K}$ are noted. This is mainly due to the strong diurnal variability in $T_{s}$ over the land that is not resolved by ERA. Also, ERA fails to capture the temperature inversion at about $850 \mathrm{mb}$ present in the observations on 31 December.

The longwave radiative effects of profile differences are now examined, using the Forster and Shine (1997) radiation scheme. For these computations the absorption and emission from water vapor, carbon dioxide, ozone, nitrous oxide, and methane were included. Profiles were interpolated onto a 183-point vertical grid containing surface observations and values every $5 \mathrm{mb}$ from 1000 


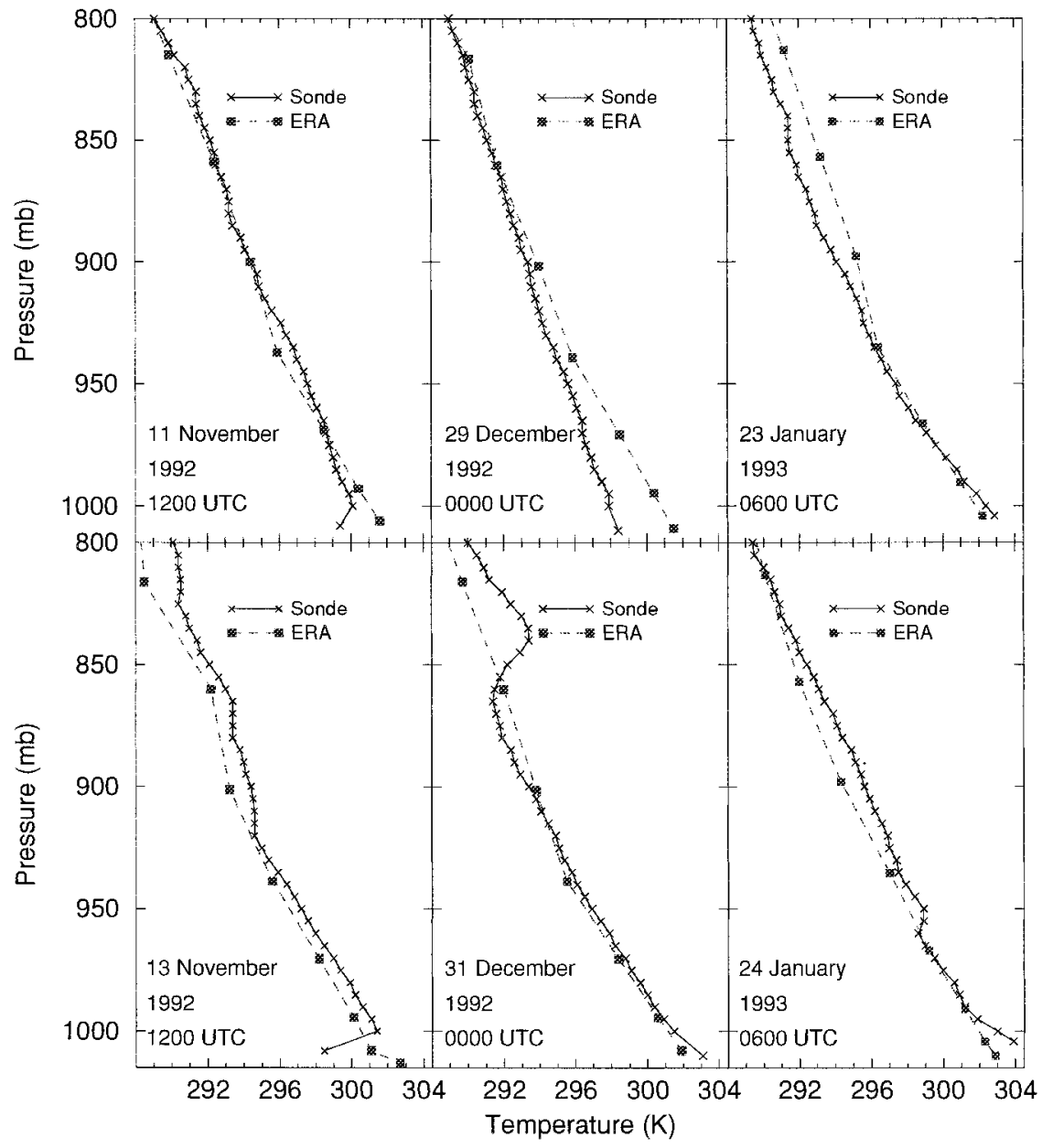

FIG. 8. ERA and Kavieng radiosonde profiles of temperature between $800 \mathrm{mb}$ and the surface. Location: $2.6^{\circ} \mathrm{S}, 150.8^{\circ} \mathrm{E}$

to $105 \mathrm{mb}$, above which there are two levels (at 75 and $25 \mathrm{mb}$ ) that were prescribed by the tropical standard atmosphere. Ozone was interpolated from the standard profile. Nitrous oxide and methane concentrations were assumed constant through the profile at 310 and 1720 ppbv, respectively, and carbon dioxide concentration was set at 360 ppmv. The effects of aerosols were not accounted for.

TABLE 2. Narrowband model-calculated surface downwelling longwave irradiance for ERA profiles, radiosonde profiles, and radiosonde profiles with ERA near-surface temperature (radiosonde') at $2.6^{\circ} \mathrm{S}, 150.8^{\circ} \mathrm{E}$

\begin{tabular}{lccc}
\hline \hline \multicolumn{1}{c}{ Time, date } & $\begin{array}{c}\text { ERA } \\
\left(\mathrm{W} \mathrm{m}^{-2}\right)\end{array}$ & $\begin{array}{c}\text { Radiosonde } \\
\left(\mathrm{W} \mathrm{m} ~^{-2}\right)\end{array}$ & $\begin{array}{c}\text { Radiosonde } \\
\left(\mathrm{w} \mathrm{m}^{-2}\right)\end{array}$ \\
\hline 1200 UTC 11 Nov 1992 & 418.9 & 406.5 & 415.2 \\
1200 UTC 13 Nov 1992 & 407.5 & 397.6 & 408.6 \\
0000 UTC 29 Dec 1992 & 415.9 & 404.8 & 415.3 \\
0000 UTC 31 Dec 1992 & 403.2 & 406.0 & 403.5 \\
0600 UTC 23 Jan 1993 & 419.9 & 421.9 & 421.6 \\
0600 UTC 24 Jan 1993 & 405.5 & 406.2 & 404.1 \\
Mean: & 411.8 & 407.2 & 411.4 \\
\hline
\end{tabular}

Mean calculated $\mathrm{SDL}_{\mathrm{c}}$ for the ERA profiles is $4.6 \mathrm{~W}$ $\mathrm{m}^{-2}$ greater than the mean calculated irradiance for the radiosonde profiles (Table 2). Replacing radiosonde near-surface temperatures with ERA values (radiosonde' in Table 2) highlights that much of the disparity in calculated irradiance is attributable to near-surface temperature differences rather than to profile temperature and moisture differences. Root-mean-square ERA minus radiosonde irradiance differences of $8.2 \mathrm{~W} \mathrm{~m}^{-2}$ decrease to $1.8 \mathrm{~W} \mathrm{~m}^{-2}$ for ERA minus radiosonde' values.

Although the $T_{s}$ differences over the WHOI buoy region are smaller than the differences over the Kavieng ARM region, the importance of near-surface layer temperature in determining SDL highlights the potential error in simulated $\mathrm{SDL}_{\mathrm{c}}$. Therefore specification of surface temperature and interpolation of near-surface temperature are likely to influence significantly the accuracy of simulated $\mathrm{SDL}_{\mathrm{c}}$. The interpolation of temperature between the lowest ERA model level and the surface assumed in the Edwards-Slingo radiation code is not 


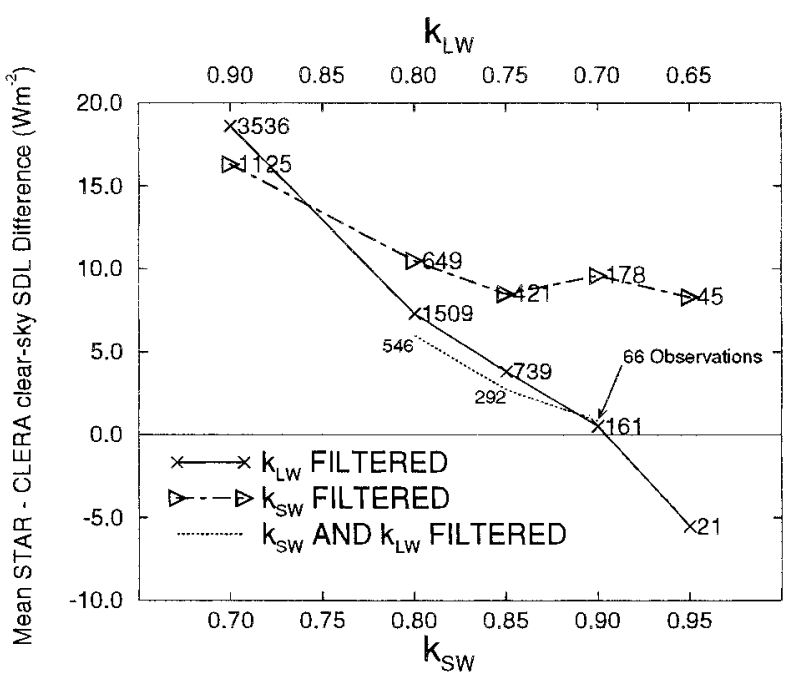

FIG. 9. Mean STAR - CLERA clear-sky SDL difference with $k_{\mathrm{sw}}$ and $k_{1 \mathrm{w}}$. Numbers within the frame denote sample size of clear-sky observations.

consistent with observations (Weller and Anderson 1996), which generally show $2.6-\mathrm{m}$ air temperature to be over $1 \mathrm{~K}$ less than surface skin temperature. This potentially introduces a bias of order $5-10 \mathrm{~W} \mathrm{~m}^{-2}$ into the simulated $\mathrm{SDL}_{\mathrm{c}}$.

\section{b. Subarctic comparison}

Figure 9 shows the mean STAR observed minus CLERA simulated $\mathrm{SDL}_{\mathrm{c}}$ difference for various values of $k_{\mathrm{sw}}$ and $k_{\mathrm{lw}}$. Numerals in the frame correspond to the number of inferred clear-sky observations $(N)$. Increasing $k_{\mathrm{sw}}$ and decreasing $k_{\mathrm{lw}}$ act to decrease $N$ and also to decrease the mean observed minus simulated $\mathrm{SDL}_{\mathrm{c}}$ dif- ference. This is consistent with the increasingly rigorous filtering of clear-sky values with increasing $k_{\mathrm{sw}}$ and decreasing $k_{\mathrm{lw}}$. However, increasing $k_{\mathrm{sw}}$ above 0.85 fails to decrease the $\mathrm{SDL}_{\mathrm{c}}$ difference further. This is likely to be due to minimal cloud contamination of observed $\mathrm{SDL}_{\mathrm{c}}$ for $k_{\mathrm{sw}}$ greater than 0.85 . Therefore there is no benefit of using higher values of $k_{\mathrm{sw}}$ because this will reduce the amount of available clear-sky data while not significantly increasing the quality of the clear-sky sampling.

For $k_{\mathrm{lw}}=0.65$, there remain only 21 suitable measurements, and the mean observed $\mathrm{SDL}_{\mathrm{c}}$ is $5.5 \mathrm{~W} \mathrm{~m}^{-2}$ less than simulated values. It is unclear whether this represents the sampling of predominantly dry profiles, or merely an error in the observed or simulated $\mathrm{SDL}_{\mathrm{c}}$; if erroneously low SDL is measured, these values are more likely to be deemed clear-sky by the longwave filtering technique because the fraction SDL/ $E$ will be small. Using $k_{\mathrm{lw}}=0.75$ produces the lowest root-meansquared $\mathrm{SDL}_{\mathrm{c}}$ difference and the strongest correlation between observed and simulated $\mathrm{SDL}_{\mathrm{c}}$. Therefore this is estimated to be the optimal value to use in the clearsky comparisons. Considering only values that are deemed clear-sky using both the solar and longwave filtering methods produces smaller still mean $\mathrm{SDL}_{\mathrm{c}}$ differences for the given $k$ values.

Figure 10 shows the correlation between simulated and observed $\mathrm{SDL}_{\mathrm{c}}$ for $k_{\mathrm{lw}}=0.75$ (Fig. 10a) and $k_{\mathrm{sw}}=$ 0.85 (Fig. 10b). Thin, diagonal lines denote a 1:1 relationship, while thick lines denote the least squares linear regression fit. Table 3 summarizes the yearly statistics for the specified values of $k_{\mathrm{lw}}$ and $k_{\mathrm{sw}}$. The lowest root-mean-square deviation for the values of $k$ considered in Table 3 is for the longwave filtering technique $\left(8.4 \mathrm{~W} \mathrm{~m}^{-2}\right)$. A strong correlation of $r=0.99$ is cal-

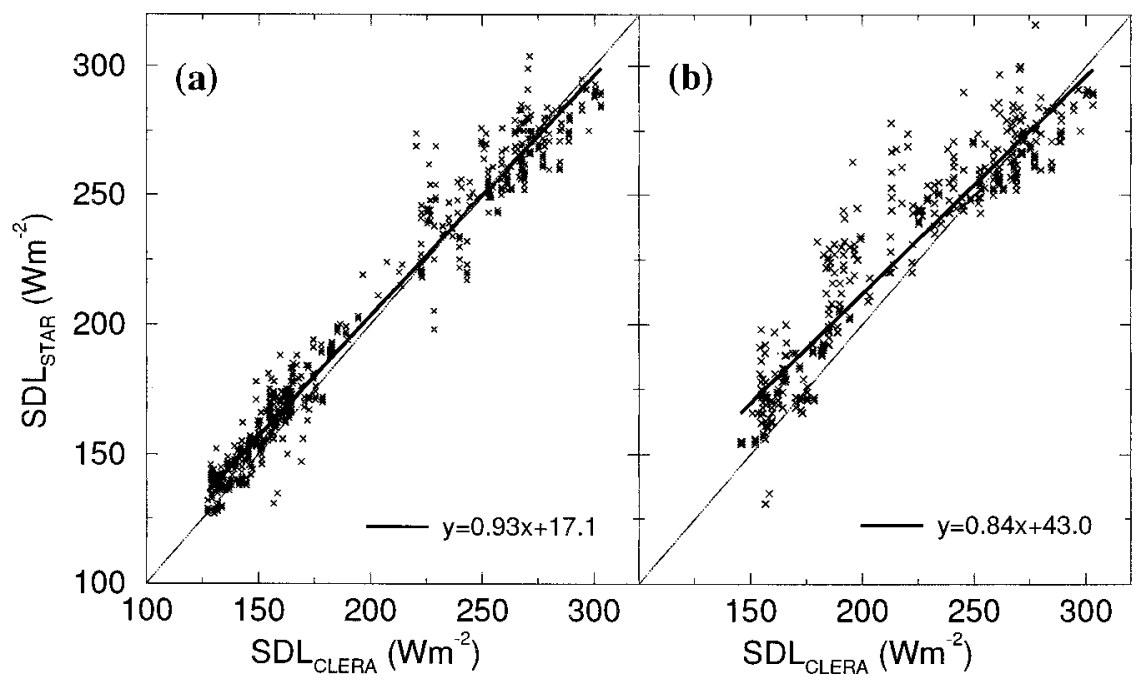

FIG. 10. Hourly STAR and CLERA SDL for (a) longwave filtered STAR clear-sky SDL and (b) shortwave filtered STAR clear-sky SDL. Diagonal lines represent STAR SDL = CLERA SDL, and thick lines represent the line of linear least squares fit to the data points. 


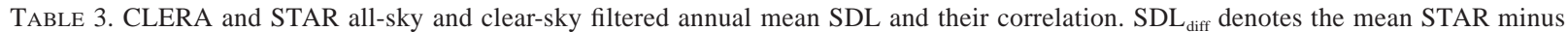
mean CLERA SDL difference, and rms denotes the rms $\mathrm{SDL}_{\text {diff }}$ difference between STAR and CLERA SDL. Here, $N$ is the number of values, and $r$ is the least squares fit correlation coefficient between STAR and CLERA SDL.

\begin{tabular}{|c|c|c|c|c|c|c|}
\hline Filtering & $\begin{array}{l}\mathrm{STAR} \mathrm{SDL}_{c} \\
\left(\mathrm{~W} \mathrm{~m}^{-2}\right)\end{array}$ & $\begin{array}{l}\text { CLERA SDL }_{c} \\
\left(\mathrm{~W} \mathrm{~m}^{-2}\right)\end{array}$ & $\begin{array}{l}\mathrm{SDL}_{\mathrm{diff}} \\
\left(\mathrm{W} \mathrm{m}^{-2}\right)\end{array}$ & $\begin{array}{l}\mathrm{Rms} \mathrm{SDL}_{\text {diff }} \\
\left(\mathrm{W} \mathrm{m}^{-2}\right)\end{array}$ & $N$ & $r$ \\
\hline None & 238.3 & 194.4 & 44.1 & 44.9 & 7995 & 0.84 \\
\hline$k_{\mathrm{w}}=0.75$ & 194.8 & 191.0 & 3.8 & 8.4 & 739 & 0.99 \\
\hline$k_{\mathrm{sw}}=0.85$ & 239.1 & 220.6 & 8.5 & 13.6 & 421 & 0.94 \\
\hline $\begin{array}{l}k_{\mathrm{lw}}=0.75, k_{\mathrm{sw}}= \\
0.85\end{array}$ & 227.3 & 224.6 & 2.7 & 9.6 & 292 & 0.98 \\
\hline
\end{tabular}

culated, although there is a tendency for the regression slope to be less than the 1:1 relationship (Fig. 10a). The gradient is stronger still when clear skies are filtered using the solar technique (Fig. 10b). The tendency for observed $\mathrm{SDL}_{\mathrm{c}}$ to be greater than simulated values for low SDL is most prominent for the solar filtering case. This is consistent with the cloud contamination of clearsky observations. Because the bias is most discernible for the shortwave filtering case, it is likely that broken cloud is the cause. While well-broken cloud allows long periods of strong solar irradiance to reach the surface, and therefore will be considered as "clear-sky" using the shortwave filtering technique, there is still a significant longwave radiation emission to the surface from these clouds. A further reason for the bias arises from errors in the ERA profiles of moisture and temperature. Generally, observed $\mathrm{SDL}_{\mathrm{c}}$ is greater than simulated values in the winter and less than simulated values in the summer, consistent with the findings of Dutton (1993).

Filtering for clear skies using both solar and longwave techniques improves slightly the correlation between

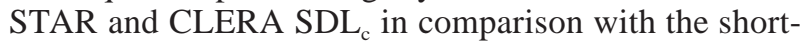
wave method only, with a root-mean-square difference of $9.6 \mathrm{~W} \mathrm{~m}^{-2}$. There is still a tendency for observed $\mathrm{SDL}_{\mathrm{c}}$ to be greater than simulated $\mathrm{SDL}_{\mathrm{c}}$ for colder, drier times and the opposite to be true for warmer, moister times. Also, the loss of all points for $\mu<0.1$ remains a disadvantage. Using the longwave technique for $\mu<$ 0.1 and either the solar method only or both filtering techniques at other times fails to decrease the residual clear-sky error. Observational errors due to the heating of the PIR dome by shortwave radiation (e.g., AladosArboledas et al. 1988) were also investigated by using the longwave technique at night only and during daylight times only (not shown). However, the observations already account for this possible error, and there is no significant difference between the residual error for the day and nighttime values.

In order to understand the reasons for the discrepancy between observed and simulated $\mathrm{SDL}_{\mathrm{c}}$ at Barrow, eight radiosonde profiles of temperature and water vapor mass mixing ratio were considered in detail. The profiles were selected for times deemed to be free of cloud by both the longwave and solar clear-sky detection methods and were compared to corresponding ERA profiles averaged over the same grid points as the simulated $\mathrm{SDL}_{\mathrm{c}}$. All radiosonde profiles were launched at 2300 UTC (close to local noon) and sampled at intervals of between 2 and $50 \mathrm{mb}$ up to about $400 \mathrm{mb}$, above which subarctic standard atmospheric water vapor and temperature profiles were assumed. Temperatures from ERA profiles at 0000 UTC are compared with radiosonde retrievals in Fig. 11. All dates correspond to the ERA profiles for the corresponding UTC.

The observed temperature profiles are generally well represented by ERA. Errors in radiative calculations due to the inadequate representation of temperature inversions (e.g., Räisänen 1996) are unlikely, therefore, to be the cause of disparities between simulated and observed irradiance. The large overestimate in surface temperatures by ERA during late April, as noted in section 2d, is highlighted in Fig. 11c for the 28 April comparison. Surface temperatures are also generally overestimated by ERA between late April and July (Figs. $11 \mathrm{c}-\mathrm{g})$. This may be due to spatial interpolation problems with the location close to the ocean, which becomes ice free between May and September. Thus the land-sea contrast becomes more pronounced than during the summer, amplifying the uncertainty introduced in interpolating between the coarse resolution ERA gridpoint profiles.

Profiles of water vapor mass mixing ratio for ERA and the eight radiosonde ascents are presented in Fig. 12. It is apparent that ERA profiles are too moist between late April and July (Figs. 12c-g), while for the remaining dates vertical profiles of moisture are in reasonable agreement. The apparent overestimate of column water vapor by ERA may be a consequence of the land-sea moisture contrast, which is particularly pronounced in July, causing the averaged ERA profiles to represent poorly the local radiosonde measurements. Alternatively, the radiosonde measurements chosen may sample localized clear-sky periods of anomalously low moisture that are not resolved on the coarse space scales and timescales given by ERA 6-h grid point values.

To quantify more fully the role of temperature and moisture differences in determining irradiance disparities, radiative calculations using the narrowband scheme were performed on the ERA and radiosonde profiles. Subarctic ozone amounts were interpolated from the standard atmosphere, and all trace gases were prescribed as in section $4 \mathrm{a}$. Temperature and column water vapor 


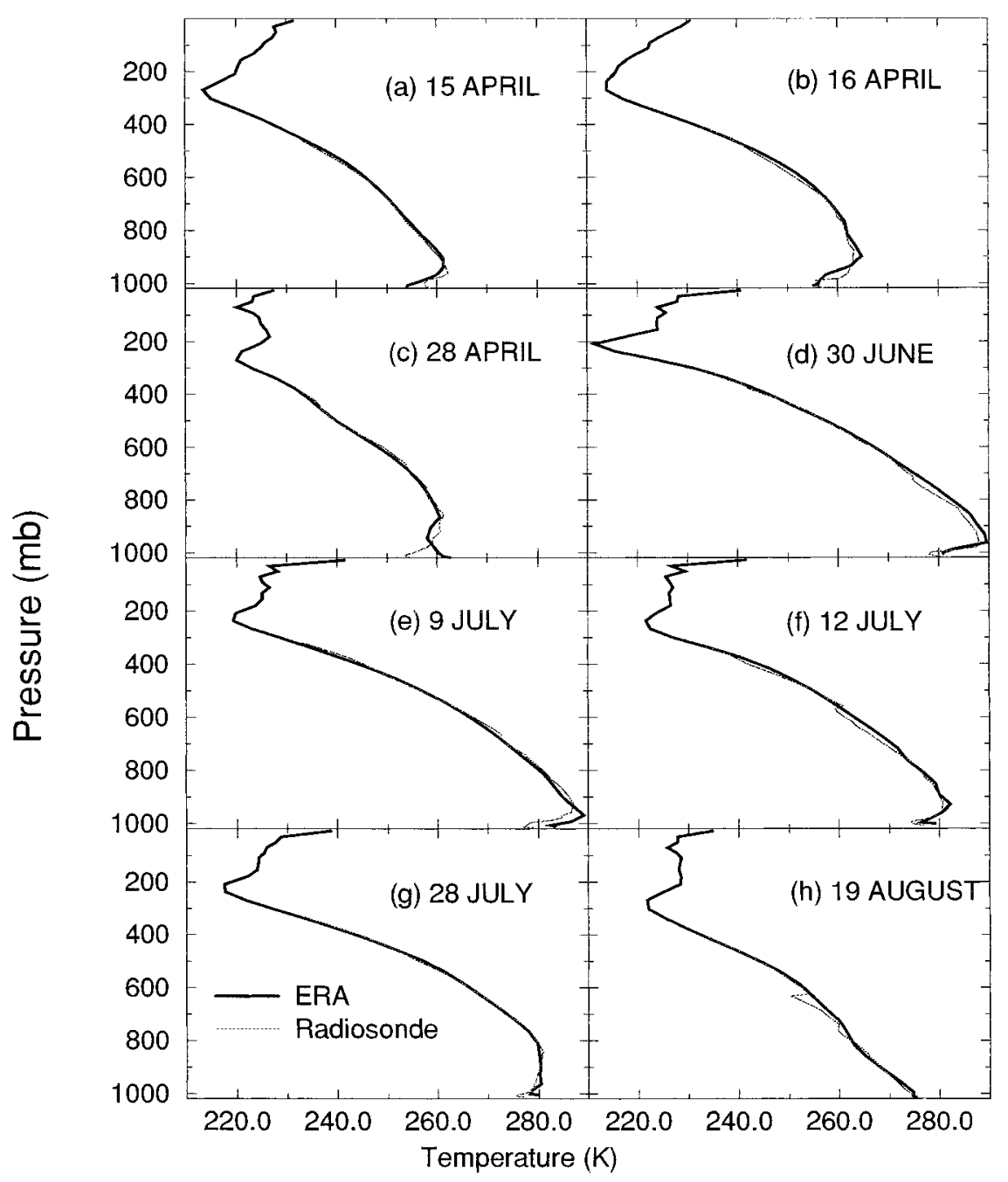

FIG. 11. Temperature profiles from radiosonde ascents over Barrow $\left(71.3^{\circ} \mathrm{N}, 156.6^{\circ} \mathrm{W}\right)$ and from ERA $\left(70^{\circ}-72.5^{\circ} \mathrm{N}, 155^{\circ}-157.5^{\circ} \mathrm{W}\right)$. Profiles are for $0000 \mathrm{UTC}$ for which the dates correspond.

differences for each profile are presented in Table 4 along with calculated $\mathrm{SDL}_{\mathrm{c}}$. Observations of SDL for the corresponding times are also shown.

Differences between radiosonde calculations of $\mathrm{SDL}_{\mathrm{c}}$ and the observations fall within the observational uncertainty of about $10 \mathrm{~W} \mathrm{~m}^{-2}$. However, differences between ERA- and radiosonde-calculated $\mathrm{SDL}_{\mathrm{c}}$ are large in some cases with the $\mathrm{SDL}_{\mathrm{c}}$ values calculated from the ERA profiles between 28 April and 28 July showing a positive bias greater than $10 \mathrm{~W} \mathrm{~m}^{-2}$ with respect to the radiosonde-calculated $\mathrm{SDL}_{\mathrm{c}}$. This may be explained by considering that surface temperature and column moisture are greater for the ERA profiles than for the radiosonde profiles. For the remaining profiles (15 and 16 April and 19 August) ERA surface temperature and column mean water vapor are less than radiosonde values, and consequently ERA-calculated $\mathrm{SDL}_{\mathrm{c}}$ is less, albeit only by about $5 \mathrm{~W} \mathrm{~m}^{-2}$, than for the radiosonde profiles.

By replacing ERA temperature or moisture profiles with those of the radiosonde observations, and on performing further radiative calculations, it is found that differences in column water vapor amounts explain over two-thirds of the calculated $\mathrm{SDL}_{\mathrm{c}}$ difference for the 30 June and 12 July profiles. Profile temperature differences explain more than two-thirds of the differences for the 15 April, while for the remaining profiles both temperature and column moisture differences contribute significantly to the $\mathrm{SDL}_{\mathrm{c}}$ discrepancy. In conclusion, it appears that the CLERA positive $\mathrm{SDL}_{\mathrm{c}}$ bias in summer months in comparison with observations is mainly due to greater total column water vapor amounts and surface temperature compared to the observed profiles at times of clear skies. A negative bias in winter is explained partially by the underestimation of surface temperature and column water vapor by ERA. The underestimation of surface temperature in winter is consistent with the ERA land surface model error discussed by Slingo et al. (1998) and Kållberg (1998). The remaining positive 


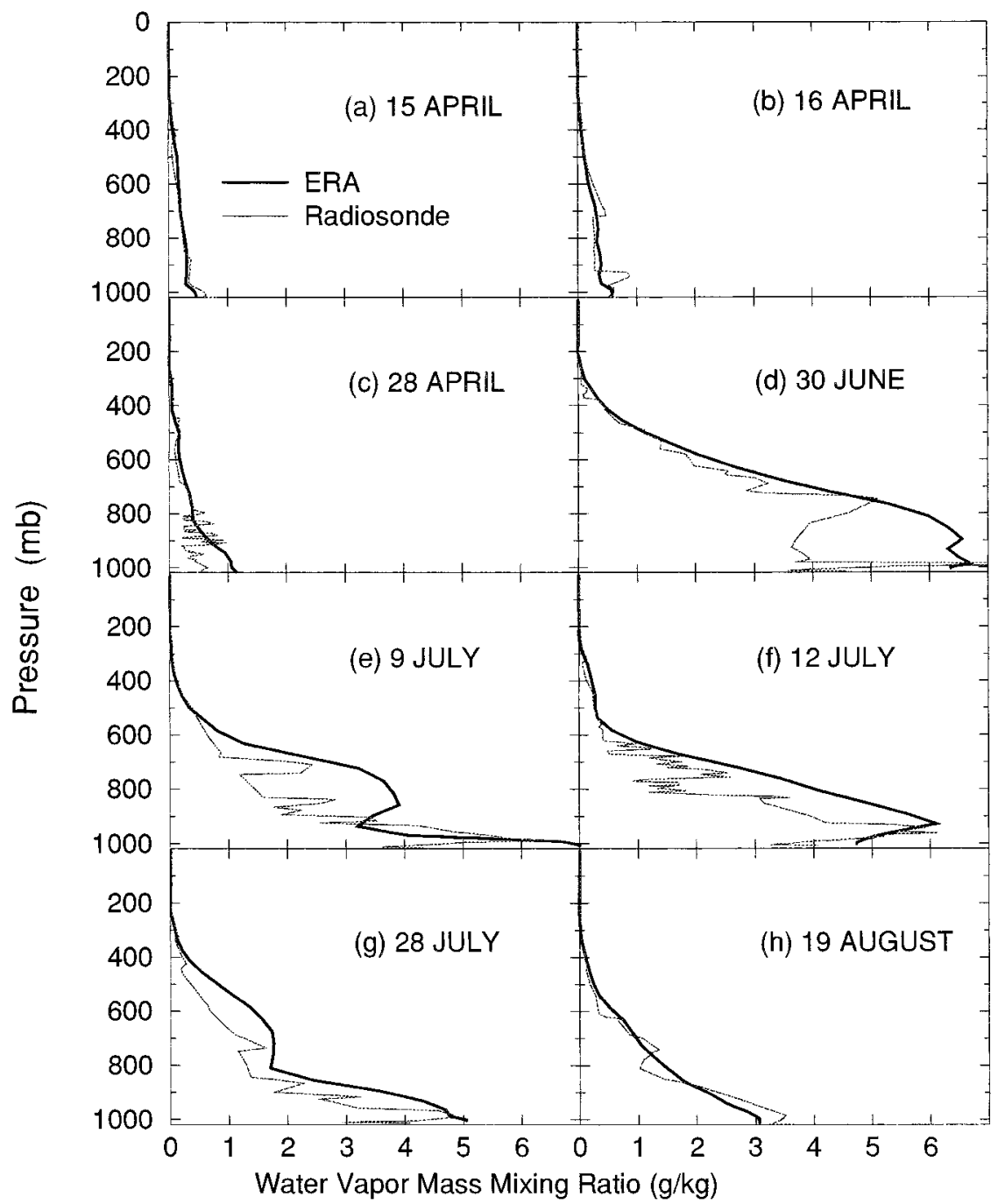

FIG. 12. Profiles of water vapor mass mixing ratio from radiosonde ascents over Barrow $\left(71.3^{\circ} \mathrm{N}\right.$, $\left.156.6^{\circ} \mathrm{W}\right)$ and from ERA $\left(70^{\circ}-72.5^{\circ} \mathrm{N}, 155^{\circ}-157.5^{\circ} \mathrm{W}\right)$. Profiles are for $0000 \mathrm{UTC}$ for which the dates correspond.

TABLE 4. Surface temperature differences $\left(\delta T_{\text {s }}\right)$, total column moisture differences $(\delta u)$, and clear-sky calculated SDL for eight profiles for ERA and radiosonde retrievals at $71.3^{\circ} \mathrm{N}, 156.6^{\circ} \mathrm{W}$. Differences are for ERA minus radiosonde values. The STAR-observed SDL is also shown for the corresponding times, and the percentage ERAradiosonde $\mathrm{SDL}_{\mathrm{c}}$ difference that is due to profile column moisture differences is given by $\delta \mathrm{SDL}_{\delta u}$.

\begin{tabular}{|c|c|c|c|c|c|c|}
\hline $\begin{array}{c}\text { Date } \\
(1992) \\
(0000 \\
\text { UTC) }\end{array}$ & $\begin{array}{l}\delta T_{s} \\
(\mathrm{~K})\end{array}$ & $\begin{array}{c}\delta u \\
\left(\mathrm{~kg} \mathrm{~m}^{-2}\right)\end{array}$ & $\begin{array}{c}\text { ERA SDL } \\
\left(\mathrm{W} \mathrm{m}^{-2}\right)\end{array}$ & $\begin{array}{c}\text { Sonde } \\
\text { SDL } \\
\left(\mathrm{W} \mathrm{m}^{-2}\right)\end{array}$ & $\begin{array}{c}\text { STAR } \\
\text { SDL } \\
\left(\mathrm{W} \mathrm{m}^{-2}\right)\end{array}$ & $\begin{array}{c}\delta \mathrm{SDL}_{\delta u} \\
(\%)\end{array}$ \\
\hline $15 \mathrm{Apr}$ & -4.9 & -0.1 & 158.4 & 163.9 & 170 & 10 \\
\hline $16 \mathrm{Apr}$ & -1.8 & -0.3 & 165.2 & 168.0 & 170 & 57 \\
\hline $28 \mathrm{Apr}$ & +6.0 & +0.6 & 178.3 & 163.7 & 171 & 37 \\
\hline 30 Jun & +0.7 & +5.8 & 294.6 & 276.8 & 271 & 77 \\
\hline $9 \mathrm{Jul}$ & +4.1 & +4.0 & 282.4 & 261.9 & 260 & 36 \\
\hline $12 \mathrm{Jul}$ & +2.2 & +4.5 & 268.1 & 253.7 & 252 & 70 \\
\hline $28 \mathrm{Jul}$ & +2.5 & +3.6 & 260.8 & 248.2 & 252 & 62 \\
\hline 19 Aug & -2.8 & -0.3 & 230.1 & 235.1 & 243 & 38 \\
\hline
\end{tabular}

observational $\mathrm{SDL}_{\mathrm{c}}$ bias may be due to cloud contamination of the clear-sky filtered irradiance or to an additional emission from aerosols not accounted for in the radiative computations.

\section{Discussion and conclusions}

A simulation of the earth's clear-sky radiation budget that uses the ECMWF reanalysis (Slingo et al. 1998) is evaluated at the surface using ground-based radiometric observations in the tropical warm pool and in the subarctic. The purpose of the comparison was to assess the ability of the simulation to represent the $\mathrm{SDL}_{\mathrm{c}}$ and its variability over a 6-h timescale for two extreme climatic regions. A further objective was to gauge the usefulness of ground-based radiometric measurements for the validation of climate model surface fluxes. The main conclusions of these comparisons are as follows. 
1) The strong dependence of $\mathrm{SDL}_{\mathrm{c}}$ on near-surface temperature and total column moisture demands the accurate estimation of these terms if a robust simulation of $\mathrm{SDL}_{\mathrm{c}}$ is to be attained.

2) The simulated $\mathrm{SDL}_{\mathrm{c}}$ tends to be greater than observed values for warmer, moister profiles, and the reverse is true for drier, colder profiles. This is consistent with Dutton (1993) and preliminary results of Wild et al. (1998). Errors in ERA temperature and moisture fields appear to explain a significant proportion of the differences. Further work is required to explain the remaining disparities.

3) Much of the tendency for simulated $\mathrm{SDL}_{\mathrm{c}}$ to be greater than observed values in the warm, moist tropical western Pacific may be explained by considering the disparity between temperature interpolation used in the simulation and the observed profile of temperature between the surface and the lowest model layer. Although the atmosphere immediately above the surface is assumed to have a temperature directly dependent on the surface skin temperature, observations show that this is not the case (e.g., Weller and Anderson 1996). The WHOI-observed 2.6-m temperatures are about $1.5 \mathrm{~K}$ less than ERA skin temperature, and this discrepancy may account for much of the overestimation of simulated $\mathrm{SDL}_{\mathrm{c}}$ in comparison with the observations.

4) Values of simulated $\mathrm{SDL}_{\mathrm{c}}$ that are greater than observed values at the subarctic station during the summer may be explained by the apparent overestimation of near-surface temperature and/or total column water vapor by ERA during times of clear skies. It is likely that the ERA profiles are at too coarse a spatial and temporal resolution to represent the local atmospheric conditions sampled by the ground-based radiometers.

5) The tendency for observed $\mathrm{SDL}_{\mathrm{c}}$ to be greater than simulated values during the winter at the subarctic station is partially explained by an underestimation in ERA near-surface temperature and total column moisture in comparison with observations. The remaining bias is likely to result from cloud contamination of the clear-sky observations that conspire to produce unrealistically high observed $\mathrm{SDL}_{\mathrm{c}}$.

The general agreement of simulated $\mathrm{SDL}_{\mathrm{c}}$ variability with observations helps to validate the simulation of the earth's clear-sky longwave radiation budget. This provides greater confidence in being able to use the simulations to test climate model variability of the budget. However, two points must be made with reference to the comparison. First, at the observational stations considered, there is likely to be a larger input of meterological data into the ERA assimilation system than in regions containing few observations. Therefore ERA profiles, and consequently also the simulation of $\mathrm{SDL}_{\mathrm{c}}$, are anticipated to be less accurate in regions of relatively few assimilated observations. A second point relates to the inadequate derivation of clear-sky irradiance observations. Both the solar and longwave clear-sky filtering techniques suffer from severe limitations (e.g., Dutton 1993) and need, at the very least, to be validated against, or used in conjunction with, comprehensive observations of cloud amount and type at the surface (e.g., Long 1996). It is paramount that independent measurements of the cloud cover be used to accomplish the clear-sky sampling of surface radiometric measurements.

To obtain a more accurate representation of the surface radiation budget, comprehensive observations of cloud amount, near-surface temperature, and total column moisture are required at the surface in conjunction with accurate in situ irradiance observations. However, the current study illustrates the potential use of surface radiometric measurements in validating climate model surface fluxes, even when additional measurements of cloud cover and radiosonde ascents are unavailable. The increasing quality and quantity of surface irradiance measurements provided by the Baseline Surface Radiation Measurement program (BSRN; Ohmura et al. 1998), by the ARM Program (e.g., Mather et al. 1998), and by the potentially excellent temporal top-of-atmosphere radiance coverage provided by geostationary satellites (e.g., Mueller 1997) are examples of observations that may be used in the future to test and to improve the representation of physical processes in both numerical weather and climate prediction models.

Acknowledgments. Sincere thanks to K. P. Shine and A. Slingo for invaluable discussion and refining of the text. I am grateful for the suggestions of the two anonymous reviewers. Help with data extraction from J. A. Pamment is also acknowledged as is additional discussion with S. P. Anderson, C. N. Long, and R. A. Weller. The STAR data are now available from the BSRN archive (http://bsrn.ethz.ch/). This work was completed as part of a Ph.D. thesis at the University of Reading and was funded by the NERC Grant GT41/95/263 under CASE award with The Met. Office.

\section{REFERENCES}

Alados-Arboledas, L., J. Vida, and J. I. Jimenez, 1988: Effects of solar radiation on the performance of pyrgeometers with silicon domes. J. Atmos. Oceanic Technol., 5, 666-670.

Dutton, E. G., 1993: An extended comparison between LOWTRAN7 computed and observed broadband thermal irradiance: Global extreme and intermediate surface conditions. J. Atmos. Oceanic Technol., 10, 326-336.

Edwards, J. M., and A. Slingo, 1996: Studies with a flexible new radiation code: I. Choosing a configuration for a large scale model. Quart. J. Roy. Meteor. Soc., 122, 689-719.

Forster, P. M. d. F., and K. P. Shine, 1997: Radiative forcing and temperature trends from stratospheric ozone depletion. J. Geophys. Res., 102, $10841-10855$.

Garratt, J. R., and A. J. Prata, 1996: Downwelling longwave fluxes at continental surfaces-A comparison of observations with GCM simulations and implications for the global land-surface radiation budget. J. Climate, 9, 646-655.

,,- L. D. Rotstayn, B. J. McAvaney, and S. Cusack, 1998: 
The surface radiation budget over oceans and continents. J. Climate, 11, 1951-1968.

Gibson, J. K., P. Kallberg, S. Uppala, A. Nomura, A. Hernandez, and E. Serrano, 1997: ERA description. ECMWF Re-analysis Project Rep. 1, ECMWF, 72 pp. [Available from European Centre for Medium-Range Weather Forcasts, Shinfield Park, Reading, Berkshire RG2 9AX, United Kingdom.]

Gupta, S. K., 1989: A parameterization for longwave surface radiation from sun-synchronous satellite data. J. Climate, 2, 305-320.

Gutzler, D. S., G. N. Kiladis, G. A. Meehl, K. M. Weickmann, and M. Wheeler, 1994: The global climate of December 1992-February 1993. Part II: Large-scale variability across the tropical western Pacific during TOGA COARE. J. Climate, 7, 16061622.

IPCC, 1996: Climate Change 1995. The Science of Climate Change. J. T. Houghton, L. G. Meira Filho, B. A. Callander, N. Harris, A. Kattenburg, and K. Maskell, Eds., Cambridge University Press, $572 \mathrm{pp}$.

Johns, T. C., R. E. Carnell, J. F. Crossley, J. M. Gregory, J. F. B. Mitchell, C. A. Senior, S. F. B. Tett, and R. A. Wood, 1997: The second Hadley Centre coupled ocean-atmosphere GCM: Model description, spinup and validation. Climate Dyn., 10, 103-134.

Kållberg, P., 1998: Aspects of the re-analysed climate. ECMWF Reanalysis Project Rep. 2, ECMWF, 89 pp. [Available from European Centre for Medium-Range Weather Forecasts, Shinfield Park, Reading, Berkshire RG2 9AX, United Kingdom.]

Long, C. N., 1996: Surface radiative energy budget and cloud forcing: Results from TOGA COARE and techniques for identifying and calculating clear sky irradiance. Ph.D. thesis, The Pennsylvania State University, 193 pp. [Available from The Pennsylvania State University, 201 Old Main, University Park, PA 16802.]

Mather, J. H., T. P. Ackerman, W. E. Clements, F. J. Barnes, M. D. Ivey, L. D. Hatfield, and R. M. Reynolds, 1998: An atmospheric radiation and cloud station in the tropical western Pacific. Bull. Amer. Meteor. Soc., 79, 627-642.

McClatchey, R. A., R. A. Fenn, J. E. A. Selby, P. E. Voltz, and J. S. Garing, 1972: Optical properties of the atmosphere. AFCRL Environmental Research Paper 411, Air Force Cambridge Research Laboratories, Bedford, MA, 113 pp. [Available from Air Force Research Laboratories, L. G. Hanscom Field, Bedford, MA 01730.]

Mueller, J., 1997: Geostationary earth radiation budget (GERB) instrument calibration plans. Adv. Space Res., 19, 1307-1316.
Ohmura, A., and Coauthors, 1998: Baseline Surface Radiation Network (BSRN/WCRP): New precision radiometry for climate research. Bull. Amer. Meteor. Soc., 79, 2115-2136.

Räisänen, P., 1996: The effect of vertical resolution on clear-sky radiation calculation: Tests with two schemes. Tellus, 48, 403423.

Ramanathan, V., 1981: The role of ocean-atmosphere interactions in the $\mathrm{CO}_{2}$ climate problem. J. Atmos. Sci., 38, 918-930.

Reynolds, R. W., and T. M. Smith, 1994: Improved global sea surface temperature analyses using optimum interpolation. J. Climate, 7, 929-948.

Rossow, W. B., and Y. C. Zhang, 1995: Calculations of surface and top of atmosphere radiative fluxes from physical quantities based on ISCCP data sets. 2. Validation and first results. J. Geophys. Res., 100, 1167-1197.

Slingo, A., J. A. Pamment, and M. J. Webb, 1998: A 15-year simulation of the clear-sky greenhouse effect using the ECMWF reanalyses: Fluxes and comparisons with ERBE. J. Climate, 11, 690-708.

Stone, R. S., 1997: Variations in western Arctic temperatures in response to cloud radiative and synoptic scale influences. J. Geophys. Res., 102, 21 769-21 776.

Waliser, D. E., W. D. Collins, and S. P. Anderson, 1996: An estimate of the surface shortwave cloud forcing over the western Pacific during TOGA COARE. Geophys. Res. Lett., 23, 519-522.

Webster, P. J., and R. Lukas, 1992: TOGA COARE: The Coupled Ocean-Atmosphere Response Experiment. Bull. Amer. Meteor. Soc., 73, 1377-1416.

Weller, R. A., and S. P. Anderson, 1996: Surface meteorology and air-sea fluxes in the western equatorial Pacific warm pool during the TOGA Coupled Ocean-Atmosphere Response Experiment. J. Climate, 9, 1959-1990.

Wild, M., A. Ohmura, H. Gilgen, and E. Roeckner, 1995: Validation of general circulation model radiative fluxes using surface observations. J. Climate, 8, 1309-1324.

,,,---- M. Giorgetta, and J. J. Morcrette, 1998: The disposition of radiative energy in the global climate system: GCM-calculated versus observational estimates. Climate Dyn., 14, 853-869.

Zhao, W., W. R. Kuhn, and S. R. Drayson, 1994: The significance of detailed structure in the boundary layer to thermal radiation at the surface in climate models. Geophys. Res. Lett., 21, 16311635. 